\section{Commentary: Channeling Goldilocks}

\author{
Betty C. Tong, MD, MHS
}

In this Invited Expert Opinion piece, Heiden and colleagues ${ }^{1}$ discuss the evidence for surveillance of lung cancer following resection and treatment. It is somewhat surprising that there is such low-level evidence for routine surveillance imaging and even more surprising that the rate of guideline concordance for "appropriate" surveillance in patients with resected lung cancer is a paltry $61 \% .^{2}$ The authors provide a sound rationale for using computed tomography (either diagnostic or low-dose variants), rather than plain chest radiograph and/or positron emission tomography scan. There are a few other concepts, however, that warrant consideration.

First, we must make a conscious decision to differentiate between imaging surveillance for lung cancer and screening for lung cancer. The surveillance patient population is at risk for both recurrence AND second primary, with the latter becoming more important approximately 2 years after treatment, as noted by the authors. However, because of their history and increased risk relative to screening patients, those patients previously treated for lung cancer should not be considered within the confines of the lung cancer screening patient population. In fact, the American College of Radiology dropped the "C" modifier for patients with previous history of lung cancer with the introduction of Lung-RADS 1.1. The rationale for this change is that "patients diagnosed and treated for lung cancer usually have annual chest CTs for disease surveillance-which is not the same as screening." ${ }^{3}$

In the absence of strong evidence regarding the surveillance interval and long-term outcomes for non-small cell lung cancer, perhaps we should also consider incorporating patient preferences to help guide screening intervals for our patients. In a recent study in patients with treated

\footnotetext{
From the Division of Thoracic and Cardiovascular Surgery, Durham, NC.

Disclosures: The author serves as a consultant for Medtronic, Inc. She is a member of the National Comprehensive Cancer Network Lung Cancer Screening Guidelines committee (no compensation)

The Journal policy requires editors and reviewers to disclose conflicts of interest and to decline handling or reviewing manuscripts for which they may have a conflict of interest. The editors and reviewers of this article have no conflicts of interest.

Received for publication Nov 13, 2020; revisions received Nov 13, 2020; accepted for publication Nov 16, 2020; available ahead of print Nov 25, 2020.

Address for reprints: Betty C. Tong, MD, MHS, Division of Thoracic and Cardiovascular Surgery, Duke University Medical Center, Durham, NC 27710 (E-mail: betty. tong@duke.edu).

J Thorac Cardiovasc Surg 2021;162:685-6

0022-5223/\$36.00

Copyright (C) 2020 by The American Association for Thoracic Surgery

https://doi.org/10.1016/j.jtcvs.2020.11.064
}

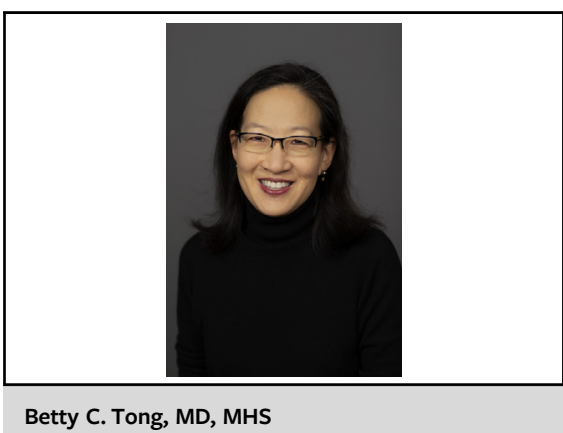

CENTRAL MESSAGE

Thoracic surgeons should weigh several considerations, including patient preferences, when making recommendations for imaging surveillance after lung cancer resection.

thyroid cancer, those classified as "strong maximizers" had significantly more doctors' visits and imaging studies related to their malignancy compared with "minimizers." We must also do what we can to minimize patient distress related to their surveillance. "Scanxiety," or scanassociated distress, has been reported in more than $80 \%$ of patients with lung cancer, with a significant deleterious impact on quality of life. ${ }^{5}$ While we cannot completely eliminate this distress, perhaps less- frequent surveillance imaging in patients who are "minimizers" might be reasonable.

Finally, the landscape of systemic treatment for lung cancer has changed dramatically over the last 10 years, and this has already had a positive impact on lung cancer survival. ${ }^{6}$ As illustrated by the recent results of the PACIFIC and ADAURA trials, the use of targeted therapies in specific patient populations has resulted in prolonged disease-free intervals and overall survival. ${ }^{7,8}$ As the number of options for treating recurrent disease continue to grow, we can only treat the disease if we (look for and) find it. As Goldilocks did in the story of the Three Bears, we must find the appropriate imaging surveillance interval for each individual patient and his or her circumstance-one that is not too short and not too long, but just right.

\section{References}

1. Heiden BT, SMP, Puri V, Kozower BD. Striking a balance: surveillance of non-small cell lung cancer after resection. J Thorac Cardiovasc Surg. 2021;162:680-4.

2. Erb CT, Su KW, Soulos PR, Tanoue LT, Gross CP. Surveillance practice patterns after curative intent therapy for stage I non-small-cell lung cancer in the Medicare population. Lung Cancer. 2016;99:200-7. 
3. ACR Lung-RADS - Update 1.1; 2019. Available at: https://www.acr.org/-/media/ ACR/Files/RADS/Lung-RADS/LungRADS-1-1-updates.pdf. Accessed November $10,2020$.

4. Evron JM, Reyes-Gastelum D, Banerjee M, Scherer LD, Wallner LP, Hamilton AS, et al. Role of patient maximizing-minimizing preferences in thyroid cancer surveillance. J Clin Oncol. 2019:37:3042-9.

5. Bauml JM, Troxel A, Epperson CN, Cohen RB, Schmitz K, Stricker C, et al. Scanassociated distress in lung cancer: quantifying the impact of "scanxiety" Lung Cancer. 2016:100:110-3.
6. Howlader N, Forjaz G, Mooradian MJ, Meza R, Kong CY, Cronin KA, et al. The effect of advances in lung-cancer treatment on population mortality. $N$ Engl J Med. 2020;383:640-9.

7. Antonia SJ, Villegas A, Daniel D, Vicente D, Murakami S, Hui R, et al. Durvalumab after chemoradiotherapy in stage III non-small-cell lung cancer. $N$ Engl J Med. 2017;377:1919-29.

8. Wu YL, Tsuboi M, He J, John T, Grohe C, Majem M, et al. Osimertinib in resected EGFR-mutated non-small-cell lung cancer. N Engl J Med. 2020;383: $1711-23$.
See Article page 680.

\section{Commentary: The value of close surveillance after lung cancer surgery: How absence of evidence is not evidence of absence}

\author{
Abbas E. Abbas, MD
}

As "the other pandemic," lung cancer kills more humans worldwide than the other 3 leading cancers combined (breast, colorectal, and prostate). ${ }^{1}$ Survival remains dismal, except in early stages when surgical resection is the standard of care, offering a 5-year survival up to $94 \%$ for stage I disease. ${ }^{2}$ After surgery, however, there are inherent risks of cancer recurrence, either the recurrent initial pulmonary cancer (RIPLC) or a new primary lung cancer (NPLC).

A retrospective study in 2013 described the results of computed tomography (CT) surveillance of 1294 patients who underwent lung cancer resection between 2004 and 2009. On follow-up, $27 \%$ redeveloped malignancy (RIPLC in $20 \%$ and NPLC in 7\%). The risk of RIPLC was $6 \%$ to $10 \%$ per person year the first 4 years after surgery but

From the Division of Thoracic Surgery, Department of Thoracic Medicine and Surgery, Temple University Hospital and Fox Chase Comprehensive Cancer Center, Philadelphia, $\mathrm{Pa}$.

Disclosures: The author reported no conflicts of interest.

The Journal policy requires editors and reviewers to disclose conflicts of interest and to decline handling or reviewing manuscripts for which they may have a conflict of interest. The editors and reviewers of this article have no conflicts of interest.

Received for publication Nov 20, 2020; revisions received Nov 20, 2020; accepted for publication Nov 23, 2020; available ahead of print Dec 3, 2020.

Address for reprints: Abbas E. Abbas, MD, Department of Thoracic Medicine and Surgery, Temple University Hospital and Fox Chase Comprehensive Cancer Center, Lewis Katz School of Medicine, 3401 N Broad St, Suite C-500, Philadelphia, PA 19035 (E-mail: abbas.abbas@temple.edu).

J Thorac Cardiovasc Surg 2021;162:686-7

0022-5223/\$36.00

Copyright $₫ 2020$ Published by Elsevier Inc. on behalf of The American Association for Thoracic Surgery

https://doi.org/10.1016/j.jtcvs.2020.11.124
Check for updates

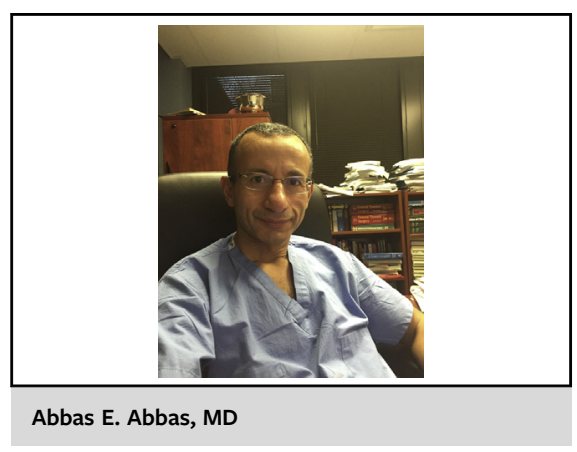

CENTRAL MESSAGE

After surgical resection of lung cancer, there is a risk of recurrence of the initial tumor or development of a new primary cancer. Despite absent evidence of benefit from frequent surveillance, there may be value in treating recurrent cancer earlier.

decreased to $2 \%$ thereafter. The risk of NPLC was $3 \%$ to $6 \%$ per person year and remained constant over time. ${ }^{3}$ In another study, 20,032 patients in the SEER database who survived at least 5 years after lung resection had a 10-year risk of NPLC of $8.36 \%$. $^{4}$ To put this risk of recurrence in perspective, the number of lobectomies or pneumonectomies performed for lung cancer in 2012 in the United States was $86,700 .^{5}$ By extrapolation, the expected number of RIPLCs $(20 \%)$ is approximately 17,000 and that of NPLC (7\%-8\%) is approximately 7000 patients.

Notwithstanding this known risk of redeveloping cancer, few studies have shown any significant benefit from postresection imaging surveillance (PRIS). A meta-analysis in 